\title{
Período total de prevenção a interferência das plantas daninhas na cultura da alface cultivar Solaris
}

\section{Total period of weed interference prevention in lettuce cv. Solaris}

\author{
Paulo Roberto Fidelis Giancotti ${ }^{1 *}$; Maria Helena Machado²; \\ Micheli Satomi Yamauti ${ }^{1}$
}

Resumo

Este trabalho foi realizado com o objetivo de determinar o período total de prevenção à interferência (PTPI) das plantas daninhas na cultura da alface do tipo crespa, cultivar Solaris. O experimento foi instalado na Universidade Estadual de Londrina, no período de outono/ inverno de 2008. A cultura permaneceu livre da interferência das plantas daninhas desde o transplante até: $0,10,20,30,40,50$ e 60 dias. O delineamento utilizado foi o de blocos casualizados com quatro repetições. A comunidade infestante da área foi composta principalmente de Bidens pilosa, Amaranthus hybridus, Oxalis corniculata, Euphorbia heterophylla, Spinacia oleracea, Commelina benghalensis e Lepidium virginicum. As massas seca e fresca das plantas daninhas e o número de folhas da cultura foram determinados. Admitindo-se $5 \%$ de tolerância na redução da produtividade da cultura, o período total de prevenção à interferência (PTPI) ocorreu 21 dias após o transplante. A interferência das plantas daninhas durante todo o ciclo de vida da alface reduziu a produtividade em $25 \%$.

Palavras-chave: Lactuca sativa L, matointerferência, competição

\begin{abstract}
This research work aimed to determine the total period of interference of weeds prevention of lettuce cultivar Solaris. The experiment was conducted in Universidade Estadual de Londrina, in the period of autumn/ winter of 2008. The lettuce crop remained free from weed interference from emergence up to $0,10,20,30$, 40, 50 e 60 days. The experiment was arranged in a randomized block design with four replications. The weed community was composed by Bidens pilosa, Amaranthus hybridus, Oxalis corniculata, Euphorbia heterophylla, Spinacia oleracea, Commelina benghalensis e Lepidium virginicum. It was determined dry and fresh matter of weeds, and number of lettuce leaves. Assuming a tolerance of $5 \%$ for crop production decrease, it was verified that the total period of interference prevention (TPIP) occurred up to 21 days after transplanting. Weed interference throughout the crop cycle reduced $25 \%$ of its yield.
\end{abstract}

Key words: Lactuca sativa $\mathrm{L}$, weed interference, competition

\footnotetext{
${ }^{1}$ Alunos do Programa de Pós Graduação em Produção Vegetal em Agronomia, Laboratório de Biologia e Manejo de Plantas Daninhas, Departamento de Biologia Aplicada à Agropecuária, Faculdade de Ciências Agrárias e Veterinárias de Jaboticabal, Universidade Estadual Paulista "Júlio de Mesquita Filho”. E-mail: paulogiancotti@gmail.com; micheliyamauti@yahoo.com.br

2 Prof ${ }^{\mathrm{a}} \mathrm{Dr}^{\mathrm{a}}$. Eng ${ }^{\mathrm{a}}$. Agr ${ }^{\mathrm{a}}$. do Departamento de Agronomia, Centro de Ciências Agrárias, Universidade Estadual de Londrina, UEL. Caixa Postal 6001, CEP: 86051-990,Londrina - Pr. E-mail: maria_helena@uel.br

* Autor para correspondência
} 
A alface (Lactuca sativa L.) é um alimento rico em Vitamina A e C, cálcio e fósforo; na medicina popular é recomendada como calmante. Ocupa espaço entre as hortaliças mais cultivadas e consumidas, sendo a mais importante das folhosas (MELHORANÇA FILHO et al., 2008). A sua maior produção se concentra no Estado de São Paulo (ANDRADE JÚNIOR; DUARTE; RIBEIRO, 1992).

Tendo em vista o produtor rural, que encontra um mercado muito competitivo, para se obter alto rendimento e qualidade da alface, é necessário o manejo intensivo de diversos fatores, incluindo o controle de plantas daninhas (SHREFLER et al., 1994). Estas competem com as plantas cultivadas pelos recursos do meio, principalmente água, luz e nutrientes, liberando substâncias alelopáticas, atuando como hospedeiros de pragas e doenças e interferindo nas práticas de colheita (ZANATTA et al., 2006). Por esse motivo, causam perdas na produção e diminuem a qualidade da cultura da alface (ROBERTS; HEWSON; RICKETTS, 1977). A interferência pode promover redução entre 30 a $45 \%$ na produtividade quando a competição ocorre nos primeiros estádios de desenvolvimento da cultura. Além disso, afetam a firmeza de suas folhas e, também, o conteúdo de nitrato e caroteno (GIANNOPOLITIS; VASSILIOU; VIZANTINOPOULOS, 1989). Em culturas folhosas, as plantas daninhas também favorecem a umidade das folhas, aumentando, assim, a incidência de doenças, diminuindo a qualidade do produto e o valor comercial (LORENZI, 2006).

Em culturas olerícolas, a competição entre plantas representa papel maior no processo de interferência da produção, devido ao fato das áreas destinadas ao cultivo passarem por uma exploração intensiva do solo, com alta freqüência de mobilização, elevadas taxas de fertilização e pequena restrição hídrica (PITELLI, 1985), além do grande reservatório de sementes no banco de semente do solo (OGG; DAWSON, 1984). Somase a isso à baixa capacidade competitiva das hortaliças (BLANCO, 1983). Para Santos et al. (2004), o aumento da habilidade competitiva da alface em relação às plantas daninhas é justificada, principalmente, pelo aumento da concentração do nutriente em torno do seu sistema radicular.

Em relação aos estudos agroecológicos sobre períodos de convivência das plantas daninhas em culturas agrícolas, têm-se o período anterior à interferência (PAI), o período total de prevenção da interferência (PTPI) e o período crítico de prevenção da interferência (PCPI) (PITELLI, 1985). O PTPI é o período a partir da emergência ou plantio em que a cultura deve ser mantida livre da interferência das plantas daninhas. $\mathrm{O}$ conhecimento de tais períodos é de extrema importância para o desenvolvimento de estratégias de manejo das plantas daninhas, indicando o intervalo de tempo quando o controle químico ou não químico poderá ser mais efetivo na prevenção de danos às plantas cultivadas (SWANTON; WEISE, 1991).

$\mathrm{O}$ grau de interferência entre as plantas cultivadas e as plantas daninhas depende de fatores relacionados à comunidade infestante (composição específica, densidade e distribuição) e à própria cultura (cultivar, densidade e método de semeadura). Depende também da duração do período de convivência, da época em que este período ocorre que é modificado pelas condições edáficas e climáticas e pelos tratos culturais (PITELLI, 1985).

A maioria dos trabalhos em que se estudou o PTPI em alface obteve-se 21 dias (CARDONA; ROMERO; POLONIA, 1977; ROBERTS; HEWSON; RICKETTS, 1977; APPEZZATO et al., 1983). Em experimentos conduzidos em junho e outubro, Blanco (1983) encontrou um PTPI de uma e duas semanas, respectivamente. Para Silva et al. (1999), com o cultivar Elisa, o PTPI foi de 14 dias. No entanto, tais estudos podem estar defasados, tendo em vista a atual mudança de flora em algumas regiões, onde certas plantas daninhas têm sido relatadas como resistentes, devido à pressão de seleção exercida pelo uso repetido de herbicidas 
com o mesmo mecanismo de ação (GRESSEL; SEGEL, 1990). Além de utilizar uma cultivar cuja competitividade ainda não foi avaliada, o presente trabalho é de relevante importância para o desenvolvimento da horticultura da região estudada, onde não há trabalhos sobre períodos de interferência em culturas olerícolas.

Assim, o objetivo desse trabalho foi avaliar a influência da matocompetição na cultura de alface tipo Crespa, cultivar Solaris, determinando o período total de prevenção da interferência (PTPI).

$\mathrm{O}$ experimento foi conduzido em área pertencente à Universidade Estadual de Londrina, no município de Londrina (PR), localizada à $23^{\circ} 23^{\prime}$ de latitude sul e $51^{\circ} 11^{\prime}$ de longitude oeste, com altitude média de $566 \mathrm{~m}$. Segundo a classificação de Köppen, o clima da região é caracterizado como Cfa - Clima subtropical, com verões quentes, geadas pouco freqüentes e tendência de concentração das chuvas nos meses de verão (IAPAR, 1994). O solo da área experimental caracteriza-se como Latossolo Vermelho Distroférrico Férrico, de textura argilosa, com as seguintes características químicas: 5,8 de $\mathrm{pH}\left(\mathrm{CaCl}_{2}\right) ; 4,026 \mathrm{mg} \mathrm{dm}^{-3}$ de P; 3,093 $\mathrm{cmol}_{\mathrm{c}} \mathrm{dm}^{-3}$ de $\mathrm{K} ; 2,475 \mathrm{~g} \mathrm{~kg}^{-1}$ de $\mathrm{Mg}$; 9,03 g. $\mathrm{kg}^{-1}$ de Ca.

O preparo da área experimental foi mecanizado, com a utilização de enxada rotativa para confecção do canteiro. Foi realizada adubação de manutenção, na proporção de $375 \mathrm{~kg} \mathrm{ha}^{-1}$ de adubo formulado 8-2816 (EMATER, 1997). Aos 25 dias após a semeadura do alface cultivar Solaris, as mudas produzidas em bandejas foram transplantadas para os canteiros.

Os tratamentos foram constituídos de períodos na ausência de plantas daninhas que foram obtidos através do arranquio manual das mesmas. A cultura permaneceu na ausência de plantas daninhas desde o transplantio até $0,10,20,30,40,50$ e 60 dias (todo o ciclo). Após esses períodos de controle, as plantas daninhas conviveram com a cultura até a colheita.

O delineamento experimental foi em blocos casualizados, com sete tratamentos em quatro repetições. As unidades experimentais consistiram de parcelas com 1,20 m x 1,80 m, com espaçamento de 0,30 m entre parcelas e 0,40 m entre blocos. Cada parcela foi constituída de quatro linhas com seis plantas com espaçamento de $0,30 \mathrm{~m}$, perfazendo uma área de $2,16 \mathrm{~m}^{2}$, sendo as linhas laterais $(0,45$ $\mathrm{m})$ consideradas bordaduras, perfazendo $0,72 \mathrm{~m}^{2} \mathrm{de}$ área útil.

Foram realizadas duas adubações nitrogenadas de cobertura com uréia, que foi aplicada 15 e 30 dias após o transplante, na quantidade de $67 \mathrm{~kg} \mathrm{ha}^{-1}$.

A colheita foi realizada 60 dias a partir do transplante, quando foram avaliadas: massa fresca das plantas e número de folhas por planta de alface.

$\mathrm{Na}$ ocasião da colheita, avaliou-se a incidência de plantas daninhas, através da coleta e identificação das mesmas, com posterior secagem das plantas por parcela. As predominantes no local do experimento foram: Bidens pilosa (picão-preto), Amaranthus hybridus (caruru), Oxalis corniculata (trevo), Euphorbia heterophylla (amendoimbravo), Spinacia oleracea (espinafre), Commelina benghalensis (trapoeraba) e Lepidium virginicum (mentruz). A coleta foi realizada com o auxílio de um quadrado de madeira com $0,25 \mathrm{~m}$ de lado $\left(0,0625 \mathrm{~m}^{2}\right.$ de área), lançado aleatoriamente na área útil da parcela. Para a obtenção da massa seca, o material foi levado à estufa, com uma temperatura de $\pm 65{ }^{\circ} \mathrm{C}$, durante um período de 72 horas, até atingir massa constante.

Os dados foram submetidos à análise de variância pelo Teste F seguida do Teste de Tukey, a 5\% de probabilidade. Para a determinação do período total de prevenção à interferência (PTPI), os dados de produtividade de massa fresca e número de folhas foram submetidos à análise de regressão pelo modelo sigmoidal de Boltzmann, considerandose aceitável $5 \%$ de perda de produtividade. Este modelo foi adaptado por Kuva et al. (2000), conforme a equação:

$$
\mathrm{Y}=\mathrm{A}_{2}+\left[\left\{\mathrm{A}_{1}-\mathrm{A}_{2}\right\} /\left\{1+\mathrm{e}^{((\mathrm{x}-\mathrm{xo}) / \mathrm{dx})}\right\}\right]
$$


Em que:

Y - expressa a produtividade comercial de alface em função dos períodos de controle;

$\mathrm{x}$ - expressa o limite superior do período de controle; $\mathrm{x}_{0}$ - expressa o limite superior do período de controle que corresponde ao valor intermediário entre a produtividade máxima e mínima;

$\mathrm{A}_{1}$ - expressa a produtividade máxima obtida nas parcelas mantidas em controle durante todo o ciclo; $\mathrm{A}_{2}$ - expressa a produtividade mínima obtida nas parcelas mantidas em convivência durante todo o ciclo;

$A_{1}-A_{2}$ - expressa a perda de produtividade;

$\mathrm{dx}$ - é o parâmetro que indica velocidade de ganho de produtividade.
A comunidade infestante, ao limitar a disponibilidade dos recursos do meio (água, luz e nutrientes), restringe o crescimento e a produção da cultura. Neste ensaio, a massa seca total da comunidade infestante foi maior no tratamento que permaneceu todo o ciclo no mato (60 dias), podendo ser assim prejudicial às plantas de alface (Tabela 1). O elevado coeficiente de variação obtido para esta característica demonstra que as plantas daninhas presentes na área se encontravam em diferentes estádios de desenvolvimento, ou seja, com diferentes acúmulos de matéria seca, comportamento este normal quando se analisa uma comunidade de plantas daninhas.

Tabela 1. Massa seca total da comunidade infestante ( $\mathrm{g} \mathrm{m}-2)$, no fim do ciclo da cultura. Londrina - PR, 2008.

\begin{tabular}{lcc}
\hline Ausência de plantas daninhas $\left(\mathbf{D A T}^{\mathbf{1}}\right)$ & Massa seca ${\mathbf{~ ( ~} \mathbf{~}^{-\mathbf{2}} \mathbf{)}}$ \\
& 0 & $97,79 \mathrm{~A}^{2}$ \\
& $0-10$ & $18,02 \mathrm{~B}$ \\
& $0-20$ & $9,94 \mathrm{~B}$ \\
& $0-30$ & $3,65 \mathrm{~B}$ \\
& $0-40$ & $0,84 \mathrm{~B}$ \\
& $0-50$ & $0,82 \mathrm{~B}$ \\
\hline DMS (Tukey) & & 59,91 \\
F (blocos) & & $1,84^{\mathrm{NS}}$ \\
F (tratamentos) & $8,42^{* *}$ \\
CV (\%) & 119,25 \\
\hline
\end{tabular}

${ }^{1}$ Dias após transplante

${ }^{2}$ Média seguidas da mesma letra, na coluna, não diferem pelo teste de Tukey a 5\%.

**Valores significativos a $1 \%$ de probabilidade

NSNão significativo

Evidencia-se que foram necessários cerca de 20 dias de controle das plantas daninhas após o transplante para que não houvesse redução do número de folhas (Figura 1). Uma vez que o número de folhas é um importante componente da produção, quanto maior esse valor e o tamanho das folhas, maior será a produção (SILVA et al., 1999). Resultados semelhantes foram encontrados por Cardona, Romero e Polonia (1977), Roberts, Hewson e Ricketts (1977) e Silva et al.(1999), para os quais a competição exercida nos primeiros estádios de crescimento do alface afetaram drasticamente o número de folhas por planta. Considerando a equação obtida neste ensaio, houve redução de 31 para 28 folhas, correspondendo a cerca de $10 \%$ de redução. 


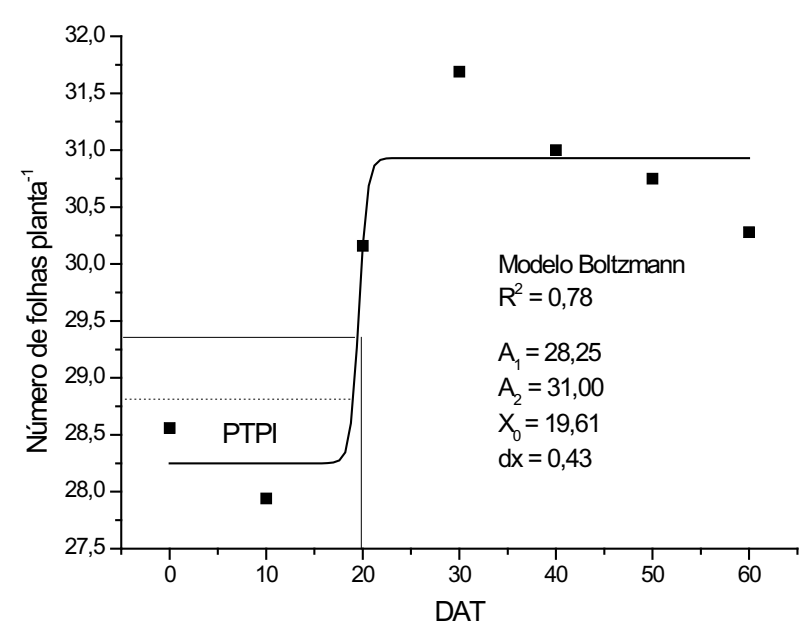

Figura 1. Número de folhas por planta de alface em função do período de convivência com as plantas daninhas, em dias após o transplante (DAT). Londrina - PR, 2008.

O controle das plantas daninhas posterior aos 21 dias após o transplante (DAT) não acarretou aumento na produção de massa fresca das plantas de alface. Portanto, o PTPI compreendeu 21 dias do ciclo agrícola da cultura após o transplante (Figura 2). Desta forma, para evitar perdas de produtividade da cultura da alface 'Solaris` devido à interferência com plantas daninhas, estas devem ser controladas por pelo menos 21 dias após o transplantio.

Analisando-se a equação, verificou-se redução na produtividade de 378 para 282 g planta $^{-1}$ em relação àquelas que foram mantidas todo período no limpo, o que representa redução de $25 \%$, a velocidade de ganho de produção foi de $2,18 \mathrm{~g}$ por dia. A redução obtida foi menor do que a constatada por Cardona, Romero e Polonia (1977), de 40 a 100\% na formação e no peso da cabeça do alface (tipo Americana) em convivência com as plantas daninhas; e Blanco (1983), de $84,5 \%$ e de $55,5 \%$ na produção do alface cv. Aurélia, respectivamente, na primavera e inverno, em convivência com Galinsoga parviflora, Bidens pilosa, Amaranthus hybridus e Raphanus raphanistrum. A comunidade infestante da área do experimento deste trabalho foi menos competitiva para a cultivar em questão ou a cultivar avaliada foi mais tolerante a interferência das plantas daninhas da área.

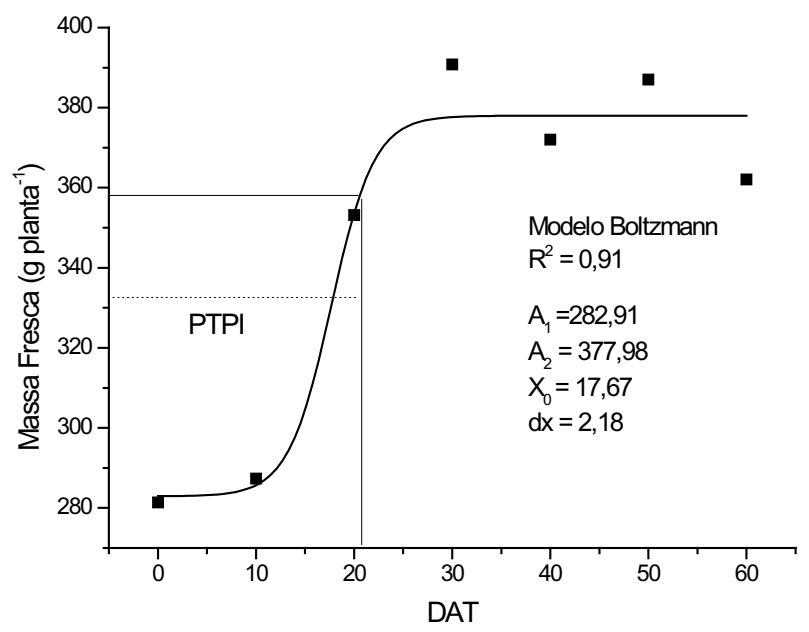

Figura 2. Produção de massa fresca de alface, em função do período de convivência com as plantas daninhas, em dias após o transplante (DAT). Londrina - PR, 2008.

O PTPI avaliado foi semelhante aos resultados obtidos por Roberts, Hewson e Ricketts (1977), Cardona, Romero e Polonia (1977), Appezzato et al. (1983), com 21 dias após o transplante em diferentes cultivares e regiões. Porém, o presente trabalho difere de Silva et al. (1999), que encontraram PTPI de 14 dias, em razão das características do cultivar Elisa, como o crescimento acelerado e alto vigor. Os diferentes resultados podem ser explicados pelo crescimento mais rápido ou mais lento das cultivares avaliadas, ocasionando o fechamento da cultura e sombreamento da entrelinha, minimizando a interferência das plantas daninhas na produção. Somado a isso, diferenças climáticas e a época de semeadura podem ter afetado a emergência e o comprimento do ciclo das plantas daninhas nos diferentes locais dos experimentos, o que interfere na competitividade da planta daninha.

A produtividade da alface foi reduzida exponencialmente com o aumento da massa seca das plantas daninhas (Figura 3). A produção de alface inicial foi estimada em $3.100 \mathrm{~g} \mathrm{~m}^{-2}$, e, com o aumento da massa seca das plantas daninhas foi reduzida para $2.205,79 \mathrm{~g} \mathrm{~m}^{-2}$, a velocidade de $1 / 17,49$ do acúmulo de massa seca das plantas daninhas. 
Conclui-se que o período total de prevenção à interferência (PTPI) ocorreu 21 dias após o transplante das mudas.

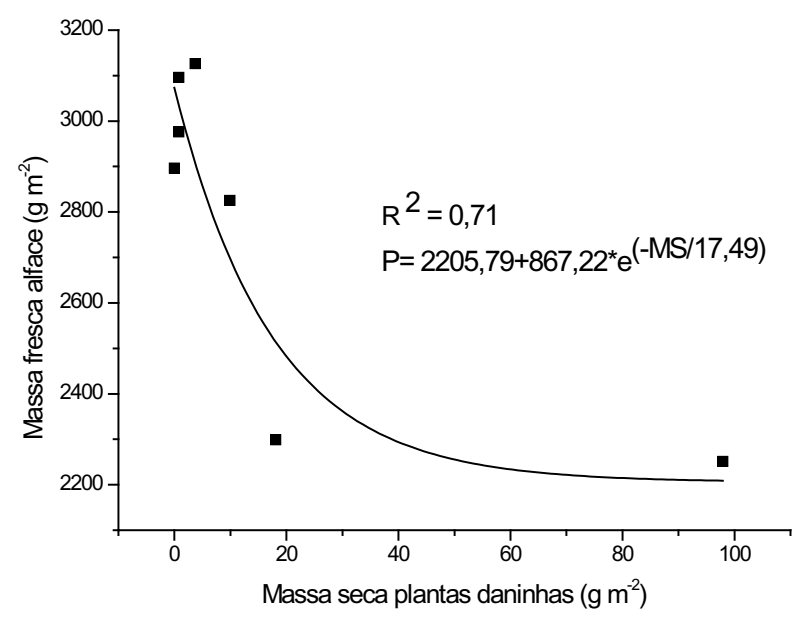

Figura 3. Efeito da massa seca $\left(\mathrm{g} \mathrm{m}^{-2}\right)$, das plantas daninhas sobre a produção da alface $\left(\mathrm{g} \mathrm{m}^{-2}\right)$. Londrina - PR, 2008.

\section{Referências}

ANDRADE JÚNIOR, A. S.; DUARTE, R. L. R.; RIBEIRO, V. Q. Resposta de cultivares de alface a diferentes níveis de irrigação . Horticultura Brasileira, Brasília, v. 10, n. 2, p. 95-97, 1992.

APPEZZATO, B.; TERAO, D.; CHRISTOFOLETI, P. J.; PIEDADE, S. M. S.; VICTORIA FILHO, R.; MINAMI, K. Competição de plantas daninhas com a cultura da alface (Lactuca sativa cv. Babá). O Solo, Piracicaba, v. 75, n. 2, p.5-10, 1983.

BLANCO, H. G. Período de competição produzido por uma comunidade natural de ervas dicotiledôneas em uma cultura de alface (Lactuca sativa L.). Arquivos do Instituto Biológico, São Paulo, SP, v. 49, n. 9, p. $247-$ 252, 1983.

CARDONA, F. P.; ROMERO, M. C. E.; POLONIA, Z. Competência de malezas en lechuga (Lactuca sativa var. capitata). Revista ICA, Bogotá, v. 12, n. 4, p. 407-420, 1977.

EMPRESA PARANAENSE DE ASSISTÊNCIA TÉCNICA E EXTENSÃO RURAL - EMATER/PR. Manual técnico de olericultura. 5. ed. rev. ampl. Curitiba: EMATER-PR. 1997, 156 p.

GIANNOPOLITIS, C. N., VASSILIOU, G.; VIZANTINOPOULOS, S. Effects of weed interference and herbicides on nitrate and carotene accumulation in lettuce. Journal Agricultural Food Chemistry, Washington, v. 37, p. 312-315, 1989.
GRESSEL, J.; SEGEL, L. A. Modeling the effectiveness of herbicide rotations and mixtures as strategies to delay or preclude resistance. Weed Technol., Lawrence, v. 4, n. 1, p. 186-198, 1990.

INSTITUTO AGRONÔMICO DO PARANÁ - IAPAR. Cartas climáticas do estado do Paraná - 1994. Londrina: IAPAR, 1994. 45 p. (Documento, 18).

KUVA, M. A.; PITELli, R. A.; CHRISTOFFOLETI, P. J.; ALVES, P L. C. A. Períodos de interferência das plantas daninhas na cultura da cana-de-açúcar. I - tiririca. Planta Daninha, Viçosa, v. 18, n. 2, p. 241-251, 2000.

LORENZI, H. Manual de identificação e controle de plantas daninhas: plantio direto e convencional. 6. ed. São Paulo: Instituto Plantarum, 2006. 339 p.

MELHORANÇA FILHO, A. L.; PEREIRA, M. R. R.; MARTINS, D.; CASTRO, R. M.; NASCIMENTO, M. S. Produtividade de alface cv Lucy Brown influenciada por períodos de convivência com plantas infestantes e potencial alelopático da tiririca. Biosci. J., Uberlândia, v. 24, n. 3, p. 19-23, july/sept.. 2008.

OGG, A. G. JR.; DAWSON, J. H. Time of emergence of eight weed species. Weed Science, Champaign, v. 32, n. 3, p. 327-335, 1984.

PITELLI, R. A. Interferência de plantas daninhas em culturas agrícolas. Inf. Agropec., Belo Horizonte, v. 11, n. 129 , p. 16-27, 1985.

ROBERTS, H. A.; HEWSON, R. T.; RICKETTS, M. E. Weed competition in drilled summer lettuce. Horticult. Res., Edinburgh, v. 17, n. 4, p. 39-45, 1977.

SANTOS, B. M.; DUSKY, J. A.; STALL, W. M.; GILREATH, J. P. Influence of common lambsquarters (Chenopodium album) densities and phosphorus fertilization on lettuce. Crop Protection, Oxford, v. 23, n. 2, p. 173-176, 2004.

SHREFLER, J. W.; DUSKY, J. A.; SHILLING, D. G.; BRECKE, B. J.; SANCHEZ, C. A. Effects of phosphorus fertility on competition between lettuce (Lactuca sativa) and spiny amaranth (Amaranthus spinosus). Weed Science, Champaign, v. 42, p. 556-560, 1994.

SILVA, A. C.; SANTOS, H. S.; SCAPIM, C. A.; CONSTANTI, J. Efeitos de períodos de controle e de convivência na cultura da alface. Acta Scientiarum, Maringá, v. 21, n. 3, p. 473-478, 1999.

SWANTON, C. J.; WEISE, S. F. Integrated weed management: the rationale and approach. Weed Technology, Lawrence, v. 5, n. 3, p. 657- 663, 1991.

ZANATTA, J. F.; FIGUEIREDO, S.; FONTANA, L. C.; PROCÓPIO, S. O. Interferência de plantas daninhas em culturas olerícolas. Revista da FZVA, Uruguaiana, v. 13, n. 2, p. 39-57, 2006. 